\title{
Die ruimtelike vorm van 'n onelastiese, buigbare, geankerde kabel
}

\author{
T.P. Dreyer \\ Departement Toegepaste Wiskunde, Universiteit van Stellenbosch, Stellenbosch 7600
}

Ontvang 21 Februarie 1992; aanvaar 11 Junie 1992

\section{UITTREKSEL}

Beskou' $n$ onelastiese, perfek buigbare kabel met gegewe eksterne kragte oor die hele lengte van die kabel. Die een endpunt is vas in die oorsprong en die ander endpunt is by 'n gegewe punt $(a ; b ; c)$ in die ruimte geanker. Die vorm wat die kabel dan in die ruimte aanneem, kan met behulp van 'n sisteem van nielineêre differensiaalvergelykings gemodelleer word. In die artikel word aangetoon dat hierdie kontinue model vir die kabel altyd in terme van 'n integraal opgelos kan word. In die spesiale geval van 'n konstante (dit wil sê onafhanklik van die posisie op die kabel) eksterne krag perlengte-eenheid word die oplossing eksplisiet aangegee in terme van drie konstantes wat die trekkrag by die oorsprong beskrywe. Hierdie drie konstantes word bepaal deur die randwaardes $a, b$ en c by die ander endpunt, en moet in die algemeen met 'n numeriese metode uit die drie resulterende, gelyktydige, nielineêre vergelykings bereken word. Die resultaat van hierdie werkswyse word met 'n paar toepassings toegelig.

\section{ABSTRACT}

\section{Configuration of an inelastic flexible anchored cable}

Consider an inelastic, perfectly flexible cable with given external forces acting on the total length of the cable. The one end-point is fixed in the origin and the other end-point is anchored at a given point $(a ; b ; c)$ in space. The resulting configuration of the cable in space can be modelled by a system of non-linear differential equations. In this article it is shown that this continuous model of the cable can always be solved in terms of an integral. In the special case of a constant (i.e. independent of the position on the cable) external force per unit length the solution is given explicitly in terms of three constants that describe the tension at the origin. These three constants are determined by the boundary values $a, b$ and $c$ at the other end-point, and must be calculated in general by $a$ numerical procedure from the three resulting simultaneous non-linear equations. A few applications of this method are shown.

\section{INLEIDING}

Beskou 'n kabel wat by sy endpunte in die driedimensionele ruimte geanker is. Die deursnit van die kabel is baie klein in vergelyking met die lengte van die kabel, sodat die kabel as 'n eendimensionele voorwerp gemodelleer kan word. Die probleem om die vorm van die kabel en die trekkrag in die kabel te bepaal as daar sekere eksterne kragte op die kabel inwerk, is reeds deur verskeie navorsers soos Paul en Soler, Snyman en Vermeulen, ${ }^{2}$ en Triantafyllou ${ }^{3}$ ondersoek.

Daar is twee basiese vertrekpunte om so 'n kabel wiskundig te modelleer. In die kontinue model word die kabel as 'n aaneenlopende entiteit beskou. Daarteenoor word die kabel by die diskrete modelle benader deur of ' $n$ eindige aantal puntmassas wat met gewiglose toue verbind is, óf 'n eindige getal starre stafies wat vry by hulle endpunte kan skarnier.

By die diskrete modelle word die vergelykings van statiese ewewig van die kragte op elke puntmassa of stafie direk vanuit die wette van Meganika neergeskryf. Hieruit ontstaan dan 'n sisteem van gelyktydige nielineêre vergelykings wat eers vereenvoudig en daarna opgelos moet word. So 'n voorbeeld is deur Dreyer en Murray ${ }^{4}$ gedoen, waarin ook die voorwaardes van ekwivalensie van die puntmassa- en stafiemodelle afgelei word. 'n Alternatiewe modellering van die stafiemodel is ook deur Theron ${ }^{5}$ gedoen.

By die kontinue model lewer die modellering van so ' $n$ kabel 'n sisteem van nielineêre, gewone differensiaal- vergelykings, saam met die randwaardes wat die geankerde endpunte van die kabel beskryf. Die onafhanklike veranderlike is die booglengte s van die kabel, gemeet vanaf die een endpunt. Die afhanklike veranderlikes is die trekkrag in die kabel en die ruimtelike veranderlikes wat die posisie van elke punt op die kabel beskryf. Daar is twee opsies om die oplossing van hierdie randwaardeprobleem te probeer bepaal: 1. Die differensiaalvergelykings word as verskilvergelykings herskryf deur die booglengte $s$ te diskretiseer en die afgeleides dan met gepaste benaderings te vervang. So het Dreyer ${ }^{6}$ die resulterende sisteem differensiaalvergelykings vir verskillende gevalle in twee dimensies opgelos met behulp van die verbeterde Euler-metode en 'n skietmetode wat 'n vektor Newton-Raphson-metode gebruik.

2. 'n Poging word aangewend om direk die eksakte oplossing van die sisteem differensiaalvergelykings met analitiese metodes te bepaal. Dit is reeds gedeeltelik deur Dreyer ${ }^{7}$ vir die tweedimensionele geval gedoen.

In hierdie artikel word die kontinue model van die kabel beskou, en sal die tweede opsie hierbo gevolg word, naamlik om die oplossing met analitiese metodes te probeer bepaal.

\section{DIE KONTINUE MODEL}

Beskou ' $n$ kabel in drie dimensies wat by sy endpunte 
sodanig geanker is dat die kabel vry is om om die ankerpunte te roteer (dit wil sê die kabel is nie ingeklem nie). Die volgende basiese aanname word gemaak:

Die kabel is onelasties, perfek buighaar en sy deursnit is baie kleiner as die lengte, sodat die kabel eendimensioneel gemodelleer kan word.

Kies reghoekige Cartesiese koördinate $(x ; y ; z)$ met die endpunt van die kabel in die oorsprong. Die ander endpunt is geanker by die vaste punt $(a ; b ; c)$ waar die getalle $a, b$, en $c$ vooraf gegee is. Dui die lengte van die kabel vanaf die oorsprong tot by enige punt $(x ; y ; z)$ op die kabel deur $\mathrm{s}$ aan. Die totale lengte $L$ van die kabel is bekend. Die grootte van die trekkrag in die kabel by die punt $(\mathrm{x} ; \mathrm{y} ; z)$ word deur $\mathrm{T}(\mathrm{s})$ aangedui. Per definisie is $T(s)$ altyd nienegatief. Die volgende strenger aanname word vereis:

Die grootte van die trekkrag $T(s)$ is positief oor die hele lengte van die kabel.

As die trekkrag by 'n sekere punt op die kabel nul is, beteken dit fisies dat die kabel by daardie punt geknip kan word sonder dat dit die vorm waarin die kabel hang, verander. Byvoorbeeld, as 'n sterk krag op 'n baie ligte kabel inwerk naby aan een van die ophangpunte, sal die grootste deel van die kabel nie onder spanning verkeer nie, en kan dit dus enige willekeurige vorm aanneem. Die aanname beteken dus dat die kabel oor sy hele lengte onder spanning verkeer.

Die rigting van die trekkrag sal altyd in die rigting van die raaklyn wees as gevolg van die basiese aanname hierbo. Die raaklynrigting van die kabel word aangedui deur die hoeke $\theta(s)$ en $\Phi(s)$, soos getoon in figuur 1, sodat $\theta$ die hoek vanaf die positiewe z-rigting na die raaklyn en $\Phi$ die hoek vanaf die positiewe $x$-rigting na die projeksie van die raaklyn op die $(\mathrm{x} ; \mathrm{y})$-vlak is.

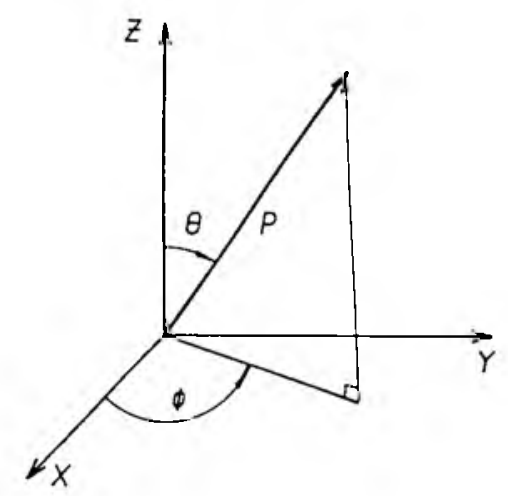

FIGUUR I: Verband tussen Cartesiese en sferiese koördinate.

Die eksterne krag wat op die kabel inwerk, is vooraf bekend. Laat $f(s), g(s)$ en $h(s)$ die komponente van hierdie krag per lengte-eenheid by die punt $(x ; y ; z)$ in die rigtings van die $x-, y$-en $z$-asse onderskeidelik wees.

As nou 'n klein element van die kabel beskou word, en die drie vergelykings van statiese ewewig van kragte daarop neergeskryf word, dan volg nadat 'n limietproses deurgevoer is, dat

$$
\text { ds }\left|\begin{array}{ll}
\mathrm{T} & \mathrm{dx} \\
\mathrm{ds}
\end{array}\right|=-\mathrm{f}(\mathrm{s})
$$

$$
\begin{aligned}
& \frac{d}{d s}\left[\begin{array}{ll}
T & d y \\
& d s
\end{array}\right]=-g(s) \\
& \left.d \quad T \begin{array}{l}
d z \\
d s
\end{array} \quad \begin{array}{ll}
d s
\end{array}\right]=-h(s)
\end{aligned}
$$

Let op dat aanvaar word dat die funksie $T(s)$ differensieerbaar is, en dat die tweede afgeleides van $x, y$ en $z$ met betrekking tot $s$ bestaan. Van Pythagoras se stelling volg eweneens na 'n limietproses dat

$$
\left(\begin{array}{l}
d x \\
d s
\end{array}\right)^{2}+\left(\begin{array}{l}
d y \\
d s
\end{array}\right)^{2}+\left(\begin{array}{l}
d z \\
d s
\end{array}\right)^{2}=1
$$

Die ankering van die twee endpunte van die kabel lewer die randwaardes:

$$
\begin{aligned}
& \left\{\begin{array}{l}
x(0)=0 \\
y(0)=0 \\
z(0)=0 .
\end{array}\right. \\
& \left\{\begin{array}{l}
x(L)=a \\
y(L)=b \\
z(L)=c .
\end{array}\right.
\end{aligned}
$$

Die vergelykings $(2.1)-(2.6)$ beskryf nou die kontinue model. Uit hierdie vergelykings moet $T(s), x(s), y(s)$, en $z(s)$ bepaal word. Let op dat die trekkragvektor by die orpsrong onbekend is.

\section{OPLOSSING VAN DIE KONTINUE MODEL}

Definieer gerieflikheidshalwe die volgende simbole:

(3.1) $F(s)=\int_{0}^{s} f(t) d t, G(s)=\int_{0}^{s} g(t) d t$ en $H(s)=\int_{0}^{s} h(t) d t$.

Van (2.1) - (2.3) volg deur direkte integrasie dat

$$
\left\{\begin{array}{l}
T x^{\prime}=-F(s)+T(0) x^{\prime}(0) \\
T y^{\prime}=-G(s)+T(0) y^{\prime}(0) \\
T z^{\prime}=-H(s)+T(0) z^{\prime}(0)
\end{array}\right.
$$

waar die aksent differensiasie met betrekking tot $\mathrm{s}$ aandui. Voer gerieflikheidshalwe die volgende notasie in:

$$
\left\{\begin{array}{l}
k=T(0) x^{\prime}(0) \\
1=T(0) y^{\prime}(0) \\
m=T(0) z^{\prime}(0)
\end{array}\right.
$$

Die vektor $\left[x^{\prime}(s), y^{\prime}(s), z^{\prime}(s)\right]$ is in die rigting van die raaklyn aan die kabel by die punt $(x(s) ; y(s) ; z(s))$ en volgens (2.4) is dit ook 'n eenheidsvektor. Dus is die konstantes $\mathrm{k}, \mathrm{l}$, en $m$ in vergelyking (3.3) presies die drie komponente van die trekkrag by die oorsprong.

As die vergelykings (3.2) elkeen gekwadreer word, en die drie vergelykings dan bymekaargetel word, volg van (2.4) dat

$$
\text { (3.4) } T^{2}=(-F+k)^{2}+(-G+1)^{2}+(-H+m)^{2} \text {. }
$$

Aangesien $T(s)$ altyd positief is volgens die aanname hierbo, kan $\mathrm{T}$ nou in die vergelykings (3.2) as volg vervang word: 




Definieer nou die volgende drie integrale



$$
\begin{aligned}
& \text { (3.6) }\left\{\begin{array}{ll}
\mathrm{J}_{1}(\mathrm{~s}, \mathrm{k}, \mathrm{l}, \mathrm{m})=\int_{0}^{\mathrm{s}} & -\mathrm{G}(\mathrm{t})+\mathrm{l} \\
0 & \mathrm{~T}(\mathrm{t}, \mathrm{k}, \mathrm{l}, \mathrm{m})
\end{array} \mathrm{dt}\right.
\end{aligned}
$$

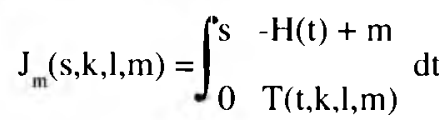

waar $\mathrm{T}(\mathrm{t}, \mathrm{k}, \mathrm{l}, \mathrm{m})$ reeds in vergelyking (3.4) gedefinieer is. As vergelykings (3.5) nou met betrekking tot $\mathrm{s}$ geintegreer word, en die randwaardes (2.5) gebruik word, volg dat

$$
\left\{\begin{array}{l}
x(s)=J_{k}(s, k, l, m) \\
y(s)=J_{1}(s, k, l, m) \\
z(s)=J_{m}(s, k, l, m)
\end{array}\right.
$$

Die konstantes $\mathrm{k}$, I en m moet nog met behulp van die randwaardes (2.6) bepaal word:

$$
\left\{\begin{array}{l}
a=J_{k}(L, k, l, m) \\
b=J_{1}(L, k, l, m) \\
c=J_{m}(L, k, l, m)
\end{array}\right.
$$

In die algemeen moet hierdie drie gelyktydige vergelykings met ' $n$ numeriese algoritme opgelos word. Dit kan byvoorbeeld met 'n Newton-Raphson-metode gedoen word. Definieer vir hierdie doel die volgende integrale:

$$
\begin{aligned}
& \mathrm{J}_{\mathrm{kk}}(\mathrm{k}, \mathrm{l}, \mathrm{m})=\int_{0}^{\mathrm{L}} \frac{(-\mathrm{F}(\mathrm{t})+\mathrm{k})^{2}}{\mathrm{~T}^{3}(\mathrm{t}, \mathrm{k}, \mathrm{l}, \mathrm{m})} \mathrm{dt} \\
& J_{k l}(k, l, m)=\int_{0}^{L} \frac{(-F(t)+k)(-G(t)+l)}{T^{3}(t, k, l, m)} d t \\
& \text { (3.9) }\left\{J_{k m}(k, l, m)=\int_{0}^{L} \frac{(-F(t)+k)(-H(t)+m)}{T^{3}(t, k, l, m)} d t\right. \\
& \mathrm{J}_{\mathrm{II}}(\mathrm{k}, \mathrm{l}, \mathrm{m})=\int_{0}^{\mathrm{L}} \frac{(-\mathrm{G}(\mathrm{t})+1)^{2}}{\mathrm{~T}^{3}(\mathrm{t}, \mathrm{k}, \mathrm{l}, \mathrm{m})} \mathrm{dt} \\
& \mathrm{J}_{\mathrm{lm}}(\mathrm{k}, \mathrm{l}, \mathrm{m})=\int_{0}^{\mathrm{L}} \frac{(-\mathrm{G}(\mathrm{t})+\mathrm{l})(-\mathrm{H}(\mathrm{t})+\mathrm{m})}{\mathrm{T}^{3}(\mathrm{t}, \mathrm{k}, \mathrm{l}, \mathrm{m})} \mathrm{dt}
\end{aligned}
$$

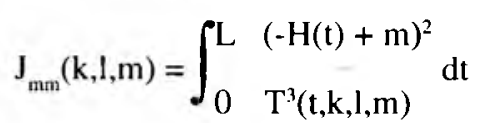

asook die volgende simmetriese matriks
(3.10) J(k,l,m)= $\begin{array}{ll:l}\mathrm{J}_{\mathrm{kk}} & \mathrm{J}_{\mathrm{kl}} & \mathrm{J}_{\mathrm{km}} \\ \mathrm{J}_{\mathrm{kl}} & \mathrm{J}_{11} & \mathrm{~J}_{\mathrm{llm}} \\ \mathrm{J}_{\mathrm{km}} & \mathrm{J}_{\mathrm{lm}} & \mathrm{J}_{\mathrm{mm}}\end{array}$

Let op dat die integrale in (3.9) net die parsiële afgeleides van die integrale in (3.6) met betrekking tot $k$, l en $\mathrm{m}$ is. Laat die i-te iterasie van $\mathrm{k}, \mathrm{l}$ en $\mathrm{m}$ deur die vektor

$$
\begin{aligned}
& k_{i} \\
& l_{i} \\
& m_{i}
\end{aligned}
$$

aangedui word, dan word die verbetering na die $(\mathrm{i}+\mathrm{l})$-te iterasie aangegee deur die vektor

$$
\begin{aligned}
& \Delta \mathrm{k} \\
& \Delta \mathrm{l} \\
& \Delta \mathrm{m}
\end{aligned}\left|=\mathrm{J}^{-1}\left(\mathrm{k}_{\mathrm{i}}, \mathrm{l}_{\mathrm{i}}, \mathrm{m}_{\mathrm{i}}\right) \quad \begin{array}{l}
\mathrm{J}_{\mathrm{k}}\left(\mathrm{L}, \mathrm{k}_{\mathrm{i}}, \mathrm{l}_{\mathrm{i}}, \mathrm{m}_{\mathrm{i}}\right)-\mathrm{a} \\
\mathrm{J}_{\mathrm{l}}\left(\mathrm{L}, \mathrm{k}_{\mathrm{i}}, \mathrm{l}_{\mathrm{i}}, \mathrm{m}_{\mathrm{l}}\right)-\mathrm{b} \\
\mathrm{J}_{\mathrm{m}}\left(\mathrm{L}, \mathrm{k}_{\mathrm{i}}, \mathrm{l}_{\mathrm{i}}, \mathrm{m}_{\mathrm{i}}\right)-\mathrm{c}
\end{array}\right|
$$

mits die determinant $|J|$ van die matriks $J\left(k_{i}, l_{i}, m_{i}\right)$ nie nul is nie. Om die nuwe iterasie te bepaal, moet nege integrale dus in (3.11) bereken word. Oor die algemeen sal 'n numeriese algoritme hiervoor gebruik moet word. Gelukkig is die integrande almal van dieselfde vorm met byna identiese noemers, sodat die programmering nie so veeleisend is nie. Verder kan 'n eerste raaiskoot van $k, 1$ en m ook redelik maklik gevind word omdat hierdie konstantes die komponente van die trekkrag by die oorsprong is.

By elke iterasie moet die determinant $|\mathrm{J}|$ bereken word om seker te maak dat dit nie te klein word nie. Dit is gerieflik om hierdie determinant in die volgende vorm te skryf:

$|\mathrm{J}|=\mathrm{J}_{\mathrm{kk}} \mathrm{J}_{1 \mathrm{I}} \mathrm{J}_{\mathrm{mm}}+2 \mathrm{~J}_{\mathrm{kl}} \mathrm{J}_{\mathrm{km}} \mathrm{J}_{\mathrm{lm}}-\mathrm{J}_{\mathrm{kl}}{ }^{2} \mathrm{~J}_{\mathrm{mm}}-\mathrm{J}_{\mathrm{km}}{ }^{2} \mathrm{~J}_{11}-\mathrm{J}_{\mathrm{lm}}{ }^{2} \mathrm{~J}_{\mathrm{kk}}$.

Nadat die waardes van $\mathrm{k}, \mathrm{l}$ en $\mathrm{m}$ bepaal is, volg dan dat die oplossing van die sisteem (2.1) - (2.6) deur die vergelykings (3.7) eksplisiet in die vorm van integrale gegee word.

\section{SPESIALE GEVAL: KONSTANTE EKSTERNE KRAG}

Laat die konstante eksterne krag deur die vektor $[\mathrm{f}, \mathrm{g}, \mathrm{h}]$ aangedui word. Dan volg van die vergelykings (3.1) dat

$$
\text { (4.1) } \quad \mathrm{F}(\mathrm{s})=\mathrm{fs} \quad \mathrm{G}(\mathrm{s})=\mathrm{gs} \quad \mathrm{H}(\mathrm{s})=\mathrm{hs}
$$

sodat die uitdrukking $\mathrm{T}(\mathrm{t}, \mathrm{k}, \mathrm{l}, \mathrm{m})$ wat in die integrale voorkom nou volgens vergelyking (3.4) reduseer na

$$
\begin{aligned}
\mathrm{T}(\mathrm{t}, \mathrm{k}, \mathrm{l}, \mathrm{m}) & =\left[(-\mathrm{ft}+\mathrm{k})^{2}+(-\mathrm{gt}+1)^{2}+(-\mathrm{ht}+\mathrm{m})^{2}\right]^{1 / 2} \\
& =\left[\left(\mathrm{f}^{2}+\mathrm{g}^{2}+\mathrm{h}^{2}\right) \mathrm{t}^{2}-2(\mathrm{fk}+\mathrm{gl}+\mathrm{hm}) \mathrm{t}+\mathrm{k}^{2}+\mathrm{l}^{2}+\mathrm{m}^{2}\right]^{1 / 2} \\
& =\left[\mathrm{A}^{2} \mathrm{t}^{2}-2 \mathrm{Bt}+\mathrm{C}^{2}\right]^{1 / 2} \\
& =\left|\mathrm{A}^{2}\left(\mathrm{t}-\frac{\mathrm{B}}{\mathrm{A}^{2}}\right)^{2}+\mathrm{C}^{2}-\frac{\mathrm{B}^{2}}{\mathrm{~A}^{2}}\right|^{1 / 2}
\end{aligned}
$$

waar A, B, en C onafhanklik van $t$ is. Van die Schwarzongelykheid in die ruimte $R^{3}$ volg dat die diskriminant van hierdie kwadratiese uitdrukking nooit positief is nie; trouens deur direkte bewerking kan die diskriminant geskryf word as 


$$
B^{2}-A^{2} C^{2}=-(f l-g k)^{2}-(f m-h k)^{2}-(g m-h l)^{2}
$$

Hieruit volg verder dat die diskriminant slegs nul kan wees as

$$
\stackrel{k}{f}=\frac{1}{g}=\stackrel{m}{h} .
$$

In terme van die vergelykings (3.3) beteken (4.4) dan dat die diskriminant slegs nul kan wees as die rigtings van die gegewe konstante eksterne krag per lengte-eenheid en die trekkrag in die oorsprong dieselfde is.

Let op dat as die diskriminant nul is, word die trekkrag nul by die punt $\mathrm{t}=\mathrm{B} / \mathrm{A}^{2}$ wat die aanname daaroor verbreek. Veronderstel dus dat die diskriminant nie nul is nie, en beskou dan die onbepaalde integraal

$$
\text { (4.5) } \quad I=\int_{T(t, k, l, m)}^{D t+E} d t
$$

wat van dieselfde vorm as die integrale in (3.6) is, en waar D en E konstantes is. Skryf gerieflikheidshalwe

(4.6) $Q=\sqrt{A^{2} C^{2}-B^{2}}$.

Voer die gebruiklike trigonometriese transformasie in:

$$
A^{2} t-B=Q \tan \theta \quad\left(-\frac{\pi}{2}<\theta<\frac{\pi}{2}\right)
$$

dan transformeer die integraal na

$$
\begin{aligned}
\mathrm{I} & =\begin{array}{l}
\mathrm{BD}+\mathrm{A}^{2} \mathrm{E} \int \sec \theta \mathrm{d} \theta+\mathrm{A}^{3} \\
\mathrm{~A}^{3}
\end{array} \\
& =\mathrm{BD}^{3} \operatorname{As} \sec \theta \tan \theta \mathrm{d} \theta
\end{aligned}
$$

As (4.7) gebruik word om terug te transformeer in terme van $t$, volg die oplossing soos in (3.6), (3.7) nou dadelik

$$
\begin{aligned}
& x(s)=A^{3} k-f B\left|A T(s, k, l, m)+A s^{2}-B\right| i
\end{aligned}
$$

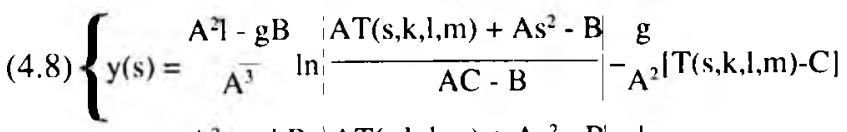

$$
\begin{aligned}
& \mathrm{z}(\mathrm{s})=\frac{\mathrm{A}^{2} \mathrm{~m}-\mathrm{hB}}{\overline{\mathrm{A}^{3}}} \ln \frac{\mathrm{AT}(\mathrm{s}, \mathrm{k}, \mathrm{l}, \mathrm{m})+\mathrm{As}^{2}-\mathrm{B} \mid \mathrm{AC}-\mathrm{B}}{\mathrm{A}^{2}}-{ }^{[\mathrm{T}(\mathrm{s}, \mathrm{k}, \mathrm{l}, \mathrm{m})-\mathrm{C}]}
\end{aligned}
$$

waar A, B, C en T in (4.2) gevind kan word.

Die oplossing kan ook in 'n ander vorm geskryf word deur hiperboliese funksies in die transformasie te gebruik:

(4.9) $A^{2} t-B=Q \sinh u$

wat dan die integraal transformeer na

$$
I=\underset{A^{3}}{B D+A^{2} E} A^{3} \cosh u .
$$

Deur terug te transformeer in terme van t volgens (4.9), en dan die betrokke bepaalde integrale in (3.6) neer te skryf, word die oplossing (3.6) vir hierdie geval verkry:

$$
x(s)=A^{3} \quad \operatorname{arcsinh} Q^{2} k+s^{2}-B \quad \operatorname{arcsinh} Q^{-} A^{2} \mid T(s, k, l, m)-C
$$

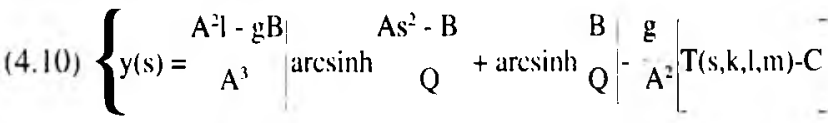

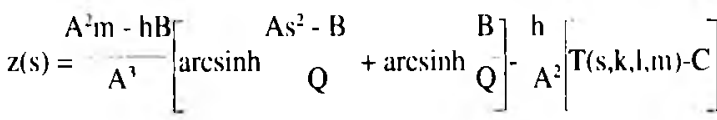

waar A, B, C, en $T$ in (4.2) en $Q$ in (4.6) gevind kan word.

Vir die geval van 'n konstante eksterne krag per lengteeenheid kan die oplossing dus eksplisiet in terme van die konstantes $\mathrm{k}, \mathrm{I}$ en $\mathrm{m}$ gevind word. Die berekening van $\mathrm{k}, \mathrm{l}$ en $m$ word net soos in Afdeling 3 gedoen met die een verskil dat die integrale in (3.9) ook eksplisiet gevind kan word. Al die integrale in (3.9) is van die vorm

$$
P=\int \frac{(\alpha t+\beta)(\sigma t+\delta)}{T^{3}} d t
$$

waar $\alpha, \beta, \sigma$ en $\delta$ konstantes is. Voer weer die transformasie (4.7) in, vereenvoudig, integreer, en transformeer weer terug nat:

$$
\begin{aligned}
& P=\frac{(\alpha \mathrm{B}+\beta)(\sigma \mathrm{B}+\delta)-\alpha \sigma \mathrm{Q}^{2}}{\mathrm{~A}^{4} \mathrm{Q}^{2}} \cdot \mathrm{At}^{2}-\mathrm{B} \frac{2 \alpha \sigma \mathrm{B}+(\alpha \delta+\sigma \beta) \mathrm{A}^{2}}{\mathrm{~A}^{4} \mathrm{~T}} \\
& +\mathrm{A}^{3} \ln \frac{\mathrm{AT}+\mathrm{A}^{2} \mathrm{t}-\mathrm{B}}{\mathrm{Q}}
\end{aligned}
$$

Met behulp van (4.11) kan die matriks $J$ in (3.10) en sy inverse in (3.11) nou direk bereken word. Alternatief kan die transformasie (4.9) ook gebruik word.

\section{SPESIALE GEVAL: HANGENDE KABEL}

Beskou die eenvoudigste geval van 'n kabel waarop slegs die gravitasiekrag inwerk. Aangesien die ruimtelike vorm van die kabel nou in 'n platvlak is, word die assestelsel so gekies dat die ophangpunt $(a ; 0 ; c)$ is, en die vorm van die kabel dus net in 'n $\mathrm{x}$-z-assestelsel beskryf kan word. In dieselfde notasie as Afdeling 4 volg dan dat:

$\mathrm{F}(\mathrm{s})=0 \quad \mathrm{H}(\mathrm{s})=-\sigma \mathrm{gs}$

van (4.1) waar g die gravitasieversnelling en $\sigma$ die massa per eenheidslengte aandui. Uit (4.2) volg verder dat

$$
\mathrm{A}=\sigma \mathrm{g} \quad \mathrm{B}=\sigma \mathrm{gm} \quad \mathrm{C}^{2}=\mathrm{k}^{2}+\mathrm{m}^{2}
$$

sodat die diskriminant in (4.3) geskryf kan word

$$
\mathrm{B}^{2}-\mathrm{A}^{2} \mathrm{C}^{2}=\sigma^{2} \mathrm{~g}^{2} \mathrm{k}^{2} \text {. }
$$

Volgens (4.10) is die oplossing dan

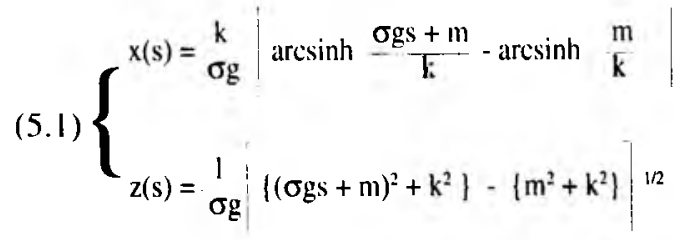

waar die konstantes $\mathrm{k}$ en $\mathrm{m}$ die komponente van die trekkrag by die oorsprong is en met behulp van 'n numeriese algoritme bepaal kan word uit die twee gelyktydige vergelykings 
(5.2)

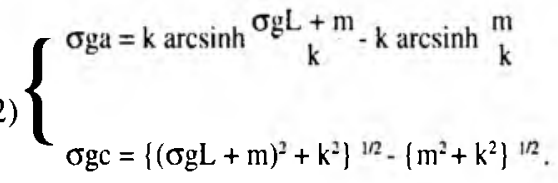

Nou kan maklik vir s uit die eerste vergelyking van (5.1) opgelos word en $\mathrm{s}$ dan in die tweede vergelyking ingestel word, om die vergelyking van die kabel in terme van $k$ en $m$ te verkry:

$$
z=\frac{1}{\sigma g}\left[|k| \cosh (\underset{k}{\sigma g x}+\operatorname{arcsinh} \underset{k}{m})-\left\{m^{2}+k^{2}\right\}^{1 / 2}\right]
$$

Maak nou die transformasie

(5.4) $\left\{\begin{array}{l}X=x+\frac{k}{\sigma g} \operatorname{arcsinh} \frac{m}{k} \\ Z=z+\frac{1}{\sigma g}\left\{m^{2}+k^{2}\right\}^{1 / 2}\end{array}\right.$

dan word vergelyking (5.3)

$$
\mathrm{Z}=\frac{|\lambda|}{\sigma \mathrm{g}} \cosh \underset{\mathrm{k}}{\sigma \mathrm{gX}}
$$

Dus is die vorm van die kabel in hierdie geval 'n gedeelte van 'n cosh-grafiek.

As verder geëis sou word dat die ophangpunte van die kabel ewe hoog moet wees (dit wil sê dat $\mathrm{c}=0$ ), volg uit die tweede vergelyking van (5.2) dat die vertikale komponent van die trekkrag by die oorsprong is

$$
\mathrm{m}=-\frac{\sigma \mathrm{gL}}{2}
$$

en die horisontale komponent $\mathrm{k}$ word gegee deur

$$
\underset{2 \mathrm{k}}{\sigma \mathrm{k} a}=\operatorname{arcsinh} \frac{\sigma \mathrm{gL}}{2 \mathrm{k}}
$$

In hierdie geval is die transformasie (5.4)

$$
\mathrm{X}=\mathrm{x}+\frac{\mathrm{a}}{2}
$$

soos verwag kan word.

\section{TOEPASSING}

Beskou 'n kabel met deursnit 0,2 meter en lengte 8 meter. Veronderstel dat die kabel onelasties en perfek buigbaar is. Die kabel word by sy endpunte opgehang sodat die endpunte vry kan skarnier. Slegs tweedimensionele toepassings word gedoen, omdat die resultate dan maklik grafies voorgestel kan word. Kies 'n reghoekige $(x, z)$-assestelsel sodat die een endpunt in die oorsprong is. Laat die ander endpunt by die punt $(3,2)$ wees.

Die voorafgaande teorie kan nou aangewend word om verskillende gevalle te ondersoek. Vir hierdie doel is 'n program in TURBO-PASCAL geskryf, wat die integrale in vergelykings (3.6) en (3.9) met behulp van Simpson se reël bereken en die gelyktydige vergelykings in (3.8) oplos met die Newton-Raphson-algoritme. Die getal subintervalle vir die berekening van die integrale word in die tabel van $(x, z)$ waardes getoon, asook die getal iterasies vir 'n akkuraatheid van minder as een sentimeter. Slegs die trekkrag by die oorsprong (dit wil sê die vektor $[\mathrm{k}, \mathrm{m}]$ soos in vergelykings (3.3)) word aangedui om ruimte te spaar; die grootte en rigting van die trekkrag by enige punt op die kabel is ook bekend. Ter illustrasie word drie gevalle getoon:

Geval 1: Konstante digtheid, geen eksterne krag nie. Veronderstel dat die kabel 'n homogene digtheid van 2000 kilogram per kubieke meter het, en dat slegs die eie gewig op die kabel inwerk (dit wil sê die geval van Afdeling 5). Met 'n aanvangsvektor $[5,-30]$ vir $[\mathrm{k}, \mathrm{m}]$ word die resultate in tabel 1 verkry, waar $s$ die booglengte van die kabel voorstel. As 100 (in plaas van 50) subintervalle geneem word, word dieselfde tabel verkry. ' $n$ Grafiek van die waardes in tabel 1 word in figuur 2 getoon.

TABEL 1

Konfigurasie van 'n homogene kabel onder eie gewig

Getal subintervalle $=50$

Getal iterasies $=11$

Horisontale trekkrag by oorsprong $=3,55$ newton Vertikale trekkrag by oorsprong $=-18,42$ newton

\begin{tabular}{|l|l|l|}
\hline s (in meter) & $x$ (in meter) & z (in meter) \\
\hline 0,00 & 0,00 & 0,00 \\
0,40 & 0,08 & $-0,39$ \\
0,80 & 0,18 & $-0,78$ \\
1,20 & 0,29 & $-1,17$ \\
1,60 & 0,42 & $-1,54$ \\
2,00 & 0,60 & $-1,90$ \\
2,40 & 0,84 & $-2,22$ \\
2,80 & 1,17 & $-2,44$ \\
3,20 & 1,56 & $-2,43$ \\
3,60 & 1,88 & $-2,21$ \\
4,00 & 2,12 & $-1,88$ \\
4,40 & 2,29 & $-1,52$ \\
4,80 & 2,43 & $-1,14$ \\
5,20 & 2,54 & $-0,76$ \\
5,60 & 2,63 & $-0,37$ \\
6,00 & 2,71 & 0,02 \\
6,40 & 2,78 & 0,42 \\
6,80 & 2,84 & 0,81 \\
7,20 & 2,90 & 1,21 \\
7,60 & 2,95 & 1,60 \\
8,00 & 3,00 & 2,00 \\
\hline
\end{tabular}

Geval 2: Konstante digtheid, eksterne puntkrag.

Veronderstel weer dat die kabel 'n homogene ditheid van 2000 kilogram per kubieke meter het, maar dat afgesien van die kabel se eie gewig ook 'n eksterne konstante krag in die middel van die kabel op die kabel inwerk. Met 'n aanvangsvektor $[5,-30]$ vir $[\mathrm{k}, \mathrm{m}]$ word die resultate in tabel 2 verkry as 'n vertikale krag van 10 newton afwaarts inwerk, en in tabel 3 as 'n krag $[1,-4]$ inwerk. Die ooreenstemmende grafieke word in figure 3 en 4 getoon. In albei gevalle lewer meer as 400 subintervalle dieselfde tabelle, terwyl 300 subintervalle waardes lewer wat by ses punte met 'n sentimeter verskil. 
TABEL 2

Konfigurasie van ' $n$ homogene kabel onder eie gewig en 'n puntbelasting van 10 newton afwaarts in die middel



FIGUUR 2: Konfigurasie van 'n homogene kabel onder eie gewig.

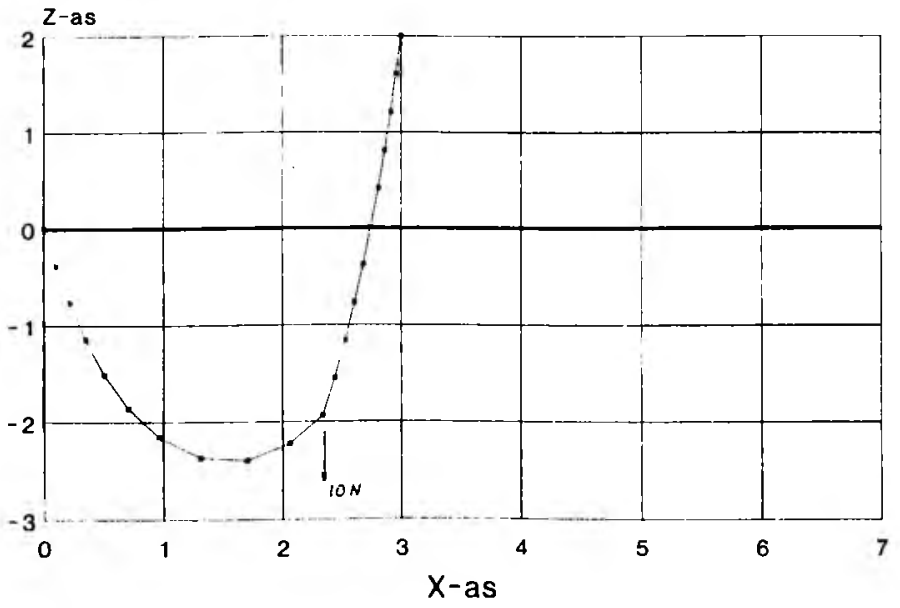

FIGUUR 3: Konfigurasie van 'n homogene kabel onder eie gewig en 'n puntbelasting van 10 newton afwaarts in die middel.



FIGUUR 4: Konfigurasie van 'n homogene kabel onder eie gewig en 'n puntbelasting van [1,-4] in newton in die Iniddel.
Getal subintervalle $=400$

Getal iterasies $=10$

Horisontale trekkrag by oorsprong $=4,45$ newton

Vertikale trekkrag by oorsprong $=-18,80$ newton

\begin{tabular}{|l|l|l|}
\hline $\mathrm{s}$ (in meter) & $\mathrm{x}$ (in meter) & $\mathrm{z}$ (in meter) \\
\hline 0,00 & 0,00 & 0,00 \\
0,40 & 0,10 & $-0,39$ \\
0,80 & 0,21 & $-0,77$ \\
1,20 & 0,35 & $-1,15$ \\
1,60 & 0,51 & $-1,52$ \\
2,00 & 0,71 & $-1,86$ \\
2,40 & 0,97 & $-2,16$ \\
2,80 & 1,31 & $-2,37$ \\
3,20 & 1,70 & $-2,40$ \\
3,60 & 2,06 & $-2,23$ \\
4,00 & 2,34 & $-1,94$ \\
4,40 & 2,44 & $-1,56$ \\
4,80 & 2,53 & $-1,17$ \\
5,20 & 2,61 & $-0,77$ \\
5,60 & 2,68 & $-0,38$ \\
6,00 & 2,74 & 0,02 \\
6,40 & 2,80 & 0,41 \\
6,80 & 2,86 & 0,81 \\
7,20 & 2,91 & 1,20 \\
7,60 & 2,96 & 1,60 \\
8,00 & 3,00 & 2,00 \\
& & \\
\hline
\end{tabular}

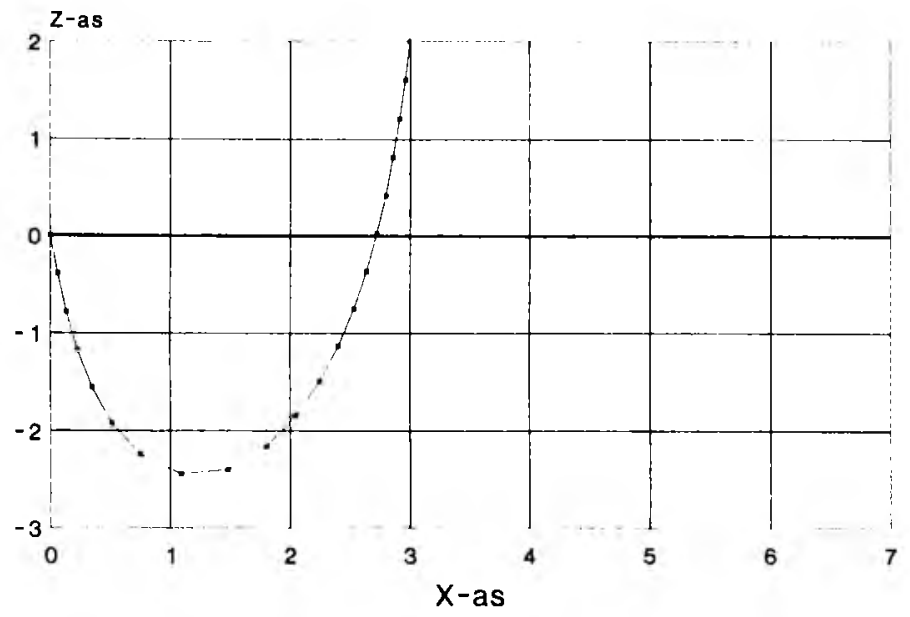

FIGUUR 5: Konfigurasie van 'n kabel met lineêr afnemende digtheid na die middelpunt, slegs onder eie gewig. 
TABEL 3

Konfigurasie van 'n homogene kabel onder eie gewig en 'n puntbelasting van $[1,-4]$ in newton in die middel

Getal subintervalle $=400$

Getal iterasies $=12$

Horisontale trekkrag by oorsprong $=4,40$ newton

Vertikale trekkrag by oorsprong $=-18,77$ newton

\begin{tabular}{|l|l|c|}
\hline $\mathrm{s}$ (in meter) & $\mathrm{x}$ (in meter) & $\mathrm{z}$ (in meter) \\
\hline 0,00 & 0,00 & 0,00 \\
0,40 & 0,10 & $-0,39$ \\
0,80 & 0,21 & $-0,77$ \\
1,20 & 0,34 & $-1,15$ \\
1,60 & 0,50 & $-1,52$ \\
2,00 & 0,70 & $-1,86$ \\
2,40 & 0,96 & $-2,17$ \\
2,80 & 1,30 & $-2,37$ \\
3,20 & 1,69 & $-2,40$ \\
3,60 & 2,05 & $-2,22$ \\
4,00 & 2,33 & $-1,94$ \\
4,40 & 2,44 & $-1,55$ \\
4,80 & 2,54 & $-1,17$ \\
5,20 & 2,62 & $-0,77$ \\
5,60 & 2,70 & $-0,38$ \\
6,00 & 2,76 & 0,01 \\
6,40 & 2,82 & 0,41 \\
6,80 & 2,87 & 0,81 \\
7,20 & 2,92 & 1,20 \\
7,60 & 2,96 & 1,60 \\
8,00 & 3,00 & 2,00 \\
\hline
\end{tabular}

Geval 3: Variërende digtheid, geen eksterne krag nie.

Veronderstel dat die digtheid van die kabel vanaf die twee endpunte lineêr na die middelpunt verminder sodat die digtheid by die endpunte 2000 kilogram per kubieke meter en die digtheid by die middelpunt 726,7 kilogram per kubieke meter is. Met 'n aanvangsvektor $[5,-30]$ vir $[\mathrm{k}, \mathrm{m}]$ word die resultate in tabel 4 verkry wat grafies in figuur 5 getoon word. As 100 (in plaas van 50) subintervalle geneem word, word presies dieselfde tabel verkry. In tabel 5 en in figuur 6 word die geval getoon as die eerste helfte van die kabel 'n digtheid van $1000 \mathrm{~kg}$ per kubieke meter het, en die ander helfte se digtheid dubbel soveel is. Slegs 60 subintervalle is nodig vir akkuraatheid tot twee desimale syfers, en net 8 iterasies lewer die antwoord met 'n aanvangsvektor $[5,-30]$. As die twee helftes van die kabel egter omgedraai word, sodat die helfte van die kabel 'n digtheid van $2000 \mathrm{~kg}$ per kubieke meter het, en die ander helfte se digtheid die helfte daarvan is, konvergeer die iterasieproses uiters stadig, en moet die integrale minstens met 200 subintervalle bereken word. Die rede hiervoor is dat die iterasieproses heen en weer rondom die antwoord spring. Die resultate vir hierdie geval word in tabel 6 en figuur 7 getoon.
TABEL 4

Konfigurasie van 'n kabel met lineêr afnemende digtheid na die middelpunt, slegs onder eie gewig

Getal subintervalle $=50$

Getal iterasies $=16$

Horisontale trekkrag by oorsprong $=1,93$ newton Vertikale trekkrag by oorsprong $=-13,85$ newton

\begin{tabular}{|l|l|l|}
\hline $\mathrm{s}$ (in meter) & $\mathrm{x}$ (in meter) & $\mathrm{z}$ (in meter) \\
\hline 0,00 & 0,00 & 0,00 \\
0,40 & 0,06 & $-0,40$ \\
0,80 & 0,13 & $-0,79$ \\
1,20 & 0,23 & $-1,18$ \\
1,60 & 0,35 & $-1,56$ \\
2,00 & 0,51 & $-1,92$ \\
2,40 & 0,75 & $-2,25$ \\
2,80 & 1,09 & $-2,44$ \\
3,20 & 1,48 & $-2,40$ \\
3,60 & 1,80 & $-2,16$ \\
4,00 & 2,05 & $-1,85$ \\
4,40 & 2,24 & $-1,50$ \\
4,80 & 2,40 & $-1,14$ \\
5,20 & 2,53 & $-0,76$ \\
5,60 & 2,64 & $-0,37$ \\
6,00 & 2,72 & 0,02 \\
6,40 & 2,80 & 0,41 \\
6,80 & 2,86 & 0,81 \\
7,20 & 2,91 & 1,20 \\
7,60 & 2,96 & 1,60 \\
8,00 & 3,00 & 2,00 \\
\hline
\end{tabular}

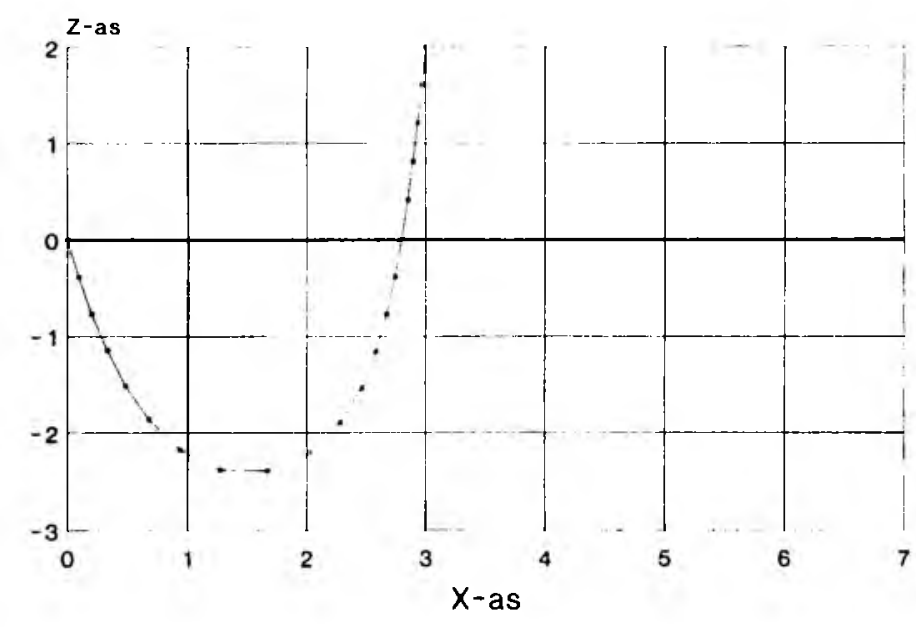

FIGUUR 6: Konfigurasie van 'n kabel met digtheid van die regter helfte dubbel die digtheid van die ander helfte, slegs onder eie gewig. 
TABEL 5

Konfigurasie van ' $n$ kabel met die digtheid van die regter helfte dubbel die digtheid van die ander helfte, slegs onder eie gewig

Getal subintervalle $=60$

Getal iterasies $=8$

Horisontale trekkrag by oorsprong $=2,09$ newton

Vertikale trekkrag by oorsprong $=-9,31$ newton

\begin{tabular}{|l|l|l|}
\hline $\mathrm{s}$ (in meter) & $\mathrm{x}$ (in meter) & $\mathrm{z}$ (in meter) \\
\hline 0,00 & 0,00 & 0,00 \\
0,40 & 0,09 & $-0,39$ \\
0,80 & 0,20 & $-0,77$ \\
1,20 & 0,33 & $-1,15$ \\
1,60 & 0,49 & $-1,52$ \\
2,00 & 0,68 & $-1,87$ \\
2,40 & 0,94 & $-2,18$ \\
2,80 & 1,28 & $-2,38$ \\
3,20 & 1,67 & $-2,40$ \\
3,60 & 2,02 & $-2,20$ \\
4,00 & 2,28 & $-1,91$ \\
4,40 & 2,46 & $-1,55$ \\
4,80 & 2,58 & $-1,17$ \\
5,20 & 2,67 & $-0,78$ \\
5,60 & 2,74 & $-0,39$ \\
6,00 & 2,80 & 0,01 \\
6,40 & 2,85 & 0,41 \\
6,80 & 2,90 & 0,81 \\
7,20 & 2,94 & 1,20 \\
7,60 & 2,97 & 1,60 \\
8,00 & 3,00 & 2,00 \\
& & \\
\hline
\end{tabular}

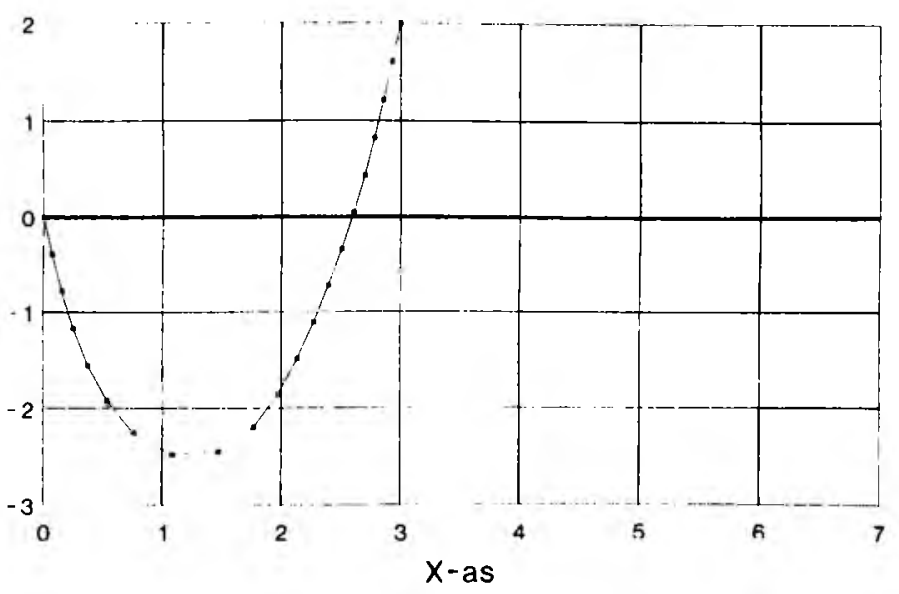

FIGUUR 7: Konfigurasie van ' $n$ kabel met digtheid van die linker helfte dubbel die digtheid van die ander helfte, slegs onder eie gewig.
TABEL 6

Konfigurasie van 'n kabel met die digtheid van die linker helfte dubbel die digtheid van die ander helfte, slegs onder eie gewig

Getal subintervalle $=200$

Getal iterasies $=148$

Horisontale trekkrag by oorsprong $=3,07$ newton

Vertikale trekkrag by oorsprong $=-18,26$ newton

\begin{tabular}{|l|l|l|}
\hline $\mathrm{s}$ (in meter) & $\mathrm{x}$ (in meter) & $\mathrm{z}$ (in meter) \\
\hline 0,00 & 0,00 & 0,00 \\
0,40 & 0,07 & $-0,39$ \\
0,80 & 0,15 & $-0,79$ \\
1,20 & 0,25 & $-1,17$ \\
1,60 & 0,37 & $-1,55$ \\
2,00 & 0,53 & $-1,92$ \\
2,40 & 0,75 & $-2,25$ \\
2,80 & 1,08 & $-2,48$ \\
3,20 & 1,47 & $-2,45$ \\
3,60 & 1,77 & $-2,20$ \\
4,00 & 1,97 & $-1,85$ \\
4,40 & 2,13 & $-1,49$ \\
4,80 & 2,27 & $-1,11$ \\
5,20 & 2,40 & $-0,73$ \\
5,60 & 2,51 & $-0,35$ \\
6,00 & 2,61 & 0,04 \\
6,40 & 2,70 & 0,43 \\
6,80 & 2,78 & 0,82 \\
7,20 & 2,86 & 1,21 \\
7,60 & 2,93 & 1,61 \\
8,00 & 3,00 & 2,00 \\
\hline
\end{tabular}

\section{LITERATUURVERWYSINGS}

1. Paul, B. \& Soler, A.I. (1972). Cable dynamics and optimum towing strategies for submersibles, Marine Technology Society Journal, Vol. 6, $34-42$.

2. Snyman, J.A. \& Vermuelen, P.J. (1979). Numerical determination of the configurations of heavy rotating chains, Applied Mathematical Modelling. Vol. 3, $232-235$.

3. Triantafyllou, M.S. (1982). Preliminary design of mooring systems, Journal Ship Research, Vol. 26, 25 - 35

4. Dreyer, T.P. \& Murray, D.M. (1985). Pre-elimination approach to the modelling of segmented representations of cable shape with application to the positioning of a towed sensor, Applied Mathematical Modelling, Vol. $9,163-169$.

5. Theron, W.F.D. (1986). Veralgemeende 2-dimensionele stafiemodel vir kabels (Verslag TW 86-3, Departement Toegepaste Wiskunde, Universiteit van Stellenbosch).

6. Dreyer, T.P. (1981). Kabelkonfigurasies in waterstrome (Tegniese nota TN-029-81, Instituut vir Maritieme Tegnologie, Simonstad) 15.

7. Dreyer, T.P. (1981). Kabelkonfigurasies in waterstome (Tegniese nota TN-029-81, Instituut vir Maritieme Tegnologie, Simonstad 17 - 23, 44 $-46,68-70$. 